\title{
DESIGN OF A HR SHAPED PATCH ANTENNA WITH DGS FOR 5G APPLICATIONS
}

\author{
Venkatesh Gudamsetty ${ }^{{ }^{1}}$, Ashok Raghava Kokkirala ${ }^{* 1}$, K. Jagadeesh Babu ${ }^{{ }^{22}}$ \\ ${ }^{*}$ Student, St. Ann's College of Engineering and Technology, Chirala, INDIA \\ *2 Professor, Dept of ECE, SACET, Chirala, INDIA. Email Id: jagan_ec@yahoo.com
}

\begin{abstract}
A HR shaped microstrip patch antenna for $5 \mathrm{G}$ application resonating at the frequency range of $26.3 \mathrm{GHz}-29.5 \mathrm{GHz}$ is described in this paper. The proposed antenna resonates at $28 \mathrm{GHz}$ frequency. The performance of antenna in terms of impedance bandwidth is analyzed by varying the position of the slot. The proposed antenna system can be widely used for the $5 \mathrm{G}$ application.
\end{abstract}

.Keywords: microstrip antenna, impedance bandwidth , return loss, 5G.

\section{INTRODUCTION}

In mobile systems, Microstrip patch antennas became popular in his world and also made the radio wireless communication easier. This is because they can be printed directly on to the circuit board, with this comfort of investigation and their fascinating radiation features patch antennas became popular. It is because of fringing fields between the patch edge and the ground surface, the microstrip patch antennas radiate. With the rapid development of wireless communication systems and increase in their applications, compact and wideband antenna design has become a challenging issue. Printed slot antennas are being used in a vast variety of communication systems to provide a wide impedance bandwidth they merged two orthogonal resonance modes.

\section{RELATED WORK}

Since 1970s, Patch antennas are being widely in use due to their special features like low profile, light weight, compact size and amenable to low-cost PCB (Printed Circuit Board) fabrication processes (Wong et al 2002, huo et al 2017). However, patch elements typically have less than $2 \%$ bandwidth and basically resonate at a single frequency (Solomon et al 1979, Guha et al 2002, K J babu et al 2010), which limits their applications in wireless communications.
Many techniques are used in the literature to enhance the bandwidth of patch antennas. A simple technique to increase the bandwidth of patch antenna is to use substrates with low dielectric constant (M Y Talha et al 2016)

The technology advanced all over the world. The microstrip rectangular patch antenna which seems like a truncated microstrip transmission line. Every generation are accomplished with some innovations and several disparities. The $5^{\text {th }}$ generation of technology started from 1G, 2G (GSM), 3G (WCDMA), 4G (LTE) and now going to flourish 5G all over the world. The fifth generation (5G) technology is extended version to the fourth generation. Such as limited bandwidth and speed. Microstrip patch antenna are widely used in satellite communication, military purpose, GPS, etc., due to its compact shape and light weight it is easy to implement.

To comply with $5 \mathrm{G}$ specifications, the antenna must have a band width larger than $1 \mathrm{GHz}$ and at least gain of $28 \mathrm{GHz}$ (Z.Ying et al 2012). The upcoming 5th generation cellular network is anticipated to exhibit a uniform GBps data throughout experiences across a wide range of user scenario.

A patch antenna is a narrow band, wide team antenna fabricated by etching the antenna element pattern in 
Meta traces bended to an insulting dielectric substrate.

The following sections describes the proposed solution for the design of a $5 \mathrm{G}$ antenna.

\section{ANTENNA DESIGN}

Figure 1 shows the structure and dimensions of the proposed antenna. A thick dielectric substrate having a low dielectric constant is desirable as it provides better radiation, larger bandwidth and better efficiency.

Here, the substrate selected for the design of the proposed antenna is FR-4(loss free) with thickness $1.6 \mathrm{~mm}$ and with low permittivity $\left(\varepsilon_{\mathrm{r}}=4.3\right)$. The dimensions of the substrate are $40 \times 30 \times 1.6 \mathrm{~mm}^{3}$.
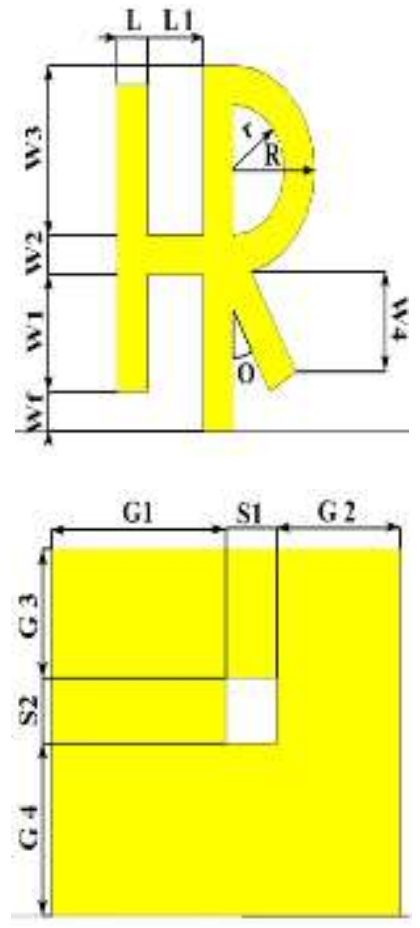

Fig.1. Structure and dimensions of the proposed antenna

A HR shaped patch of size $20 \times 25 \mathrm{~mm} 2$ of thickness $0.03 \mathrm{~mm}$ is placed on a substrate and ground patch of size $32 \times 27.8 \mathrm{~mm} 2$ of thickness $0.03 \mathrm{~mm}$.

The actual dimensions are detailed in Table 1.

$\underline{\text { Table 1. Dimensions of the proposed antenna }}$

\begin{tabular}{cccccc}
\hline $\mathrm{L}$ & $3 \mathrm{~mm}$ & $\mathrm{~W} 1$ & $9 \mathrm{~mm}$ & $\mathrm{Wf}$ & $3 \mathrm{~mm}$ \\
\hline $\mathrm{L} 1$ & $5.5 \mathrm{~mm}$ & $\mathrm{~W} 2$ & $3 \mathrm{~mm}$ & $\mathrm{O}$ & $30^{\circ}$ \\
$\mathrm{R}$ & $8 \mathrm{~mm}$ & $\mathrm{~W} 3$ & $13 \mathrm{~mm}$ & $\mathrm{~S} 1$ & $4.7 \mathrm{~mm}$ \\
$\mathrm{R}$ & $5 \mathrm{~mm}$ & $\mathrm{~W} 4$ & $8 \mathrm{~mm}$ & $\mathrm{~S} 2$ & $5 \mathrm{~mm}$ \\
$\mathrm{G} 1$ & $16 \mathrm{~mm}$ & $\mathrm{G} 2$ & $11.3 \mathrm{~mm}$ & $\mathrm{G} 3$ & $9.8 \mathrm{~mm}$ \\
\hline
\end{tabular}

A slot of $4.7 \mathrm{~mm}$ length, width $5 \mathrm{~mm}$, and thickness of $0.03 \mathrm{~mm}$ was cut on the ground as shown in the above figure. By providing slots, the lengths of the current paths on the patch are increased, leading to the gain improvement. The proposed antenna is excited by using microstrip feeding technique. The microstrip feed line is a conducting strip, usually of much smaller width compared to the radiating patch. The feed line of size $3 \times 3 \mathrm{~mm}^{2}$ is connected to the patch.

\section{EXPERIMENTAL RESULTS \& DISCUSSION}

The $S_{11}$ plot for the slot patch antenna designed in this paper is shown in Fig.2. The dimensions of the antenna are selected such that the antenna resonates at $28 \mathrm{GHz}$ with an impedance bandwidth of $3.2 \mathrm{GHz}$. The antenna is analyzed by varying the slot position. The difference of the $S_{11}$ plots for with slot and without slot are shown in Fig 2 \& Fig 3.

From Fig.2,3, it can be observed that the return loss curve is maximum with slotted ground. The returen loss curve of the antenna without slotted ground at 28 $\mathrm{GHz}$ is $-15.2 \mathrm{~dB}$. The return loss curve of the proposed antenna(with slotted ground) at $28 \mathrm{GHz}$ is $43 \mathrm{~dB}$. In order to operate the antenna efficiently, maximum power must be transferred between the transmitter and the antenna.

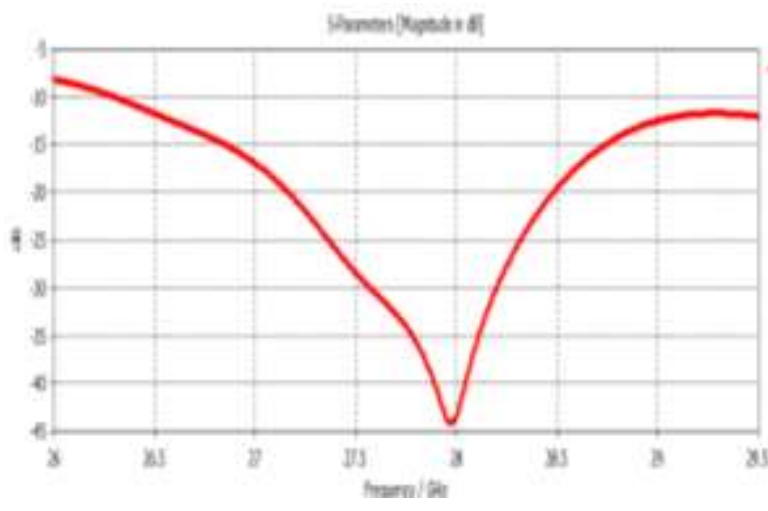

Fig.2. S-paramaters of rectangular patch antenna with defective ground structure (DGS)

Maximum power transfer can take place only when the impedance of the antenna is matched to that of the transmitter. The higher the VSWR, the greater is the mismatch. VSWR plot for the proposed antenna is shown in figure 4. From the plot, it can be observed that VSWR is less than or equal to 2 in the radiating frequency. Thus, the mismatch is much lower in the radiating band. 
THE ANNALS OF "DUNĂREA DE JOS" UNIVERSITY OF GALATI

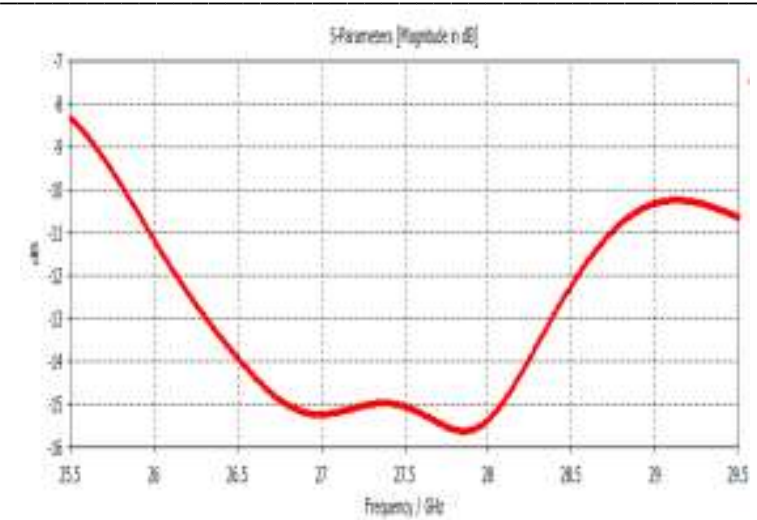

Fig.3. S-paramaters of rectangular patch antenna without defective ground structure

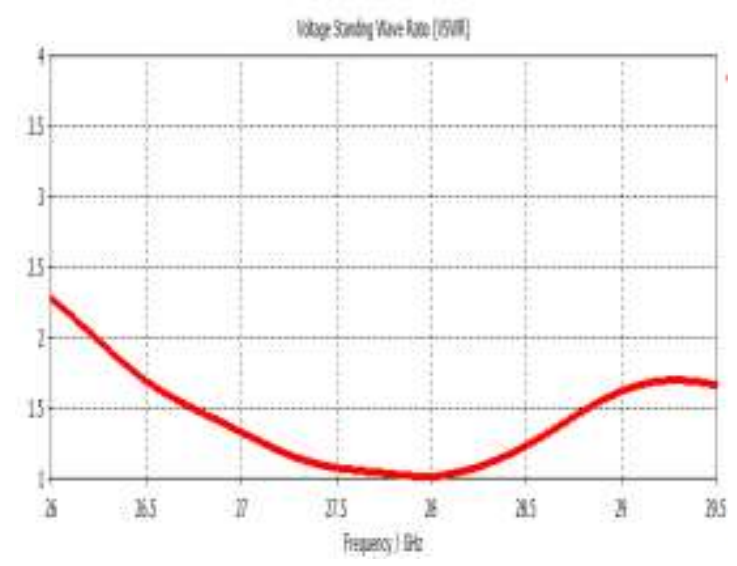

Fig.4. VSWR plot

The radiation pattern of an antenna is a plot of farfield radiation properties of an antenna as a function of the spatial co-ordinates which are specified by the elevation angle $\theta$ and the azimuth angle $\varphi$. The radiation patterns for the proposed antenna at resonating frequency $28 \mathrm{GHz}$ are shown in figure.5.

\section{Farfield Directivity Abs (Phi=90)}

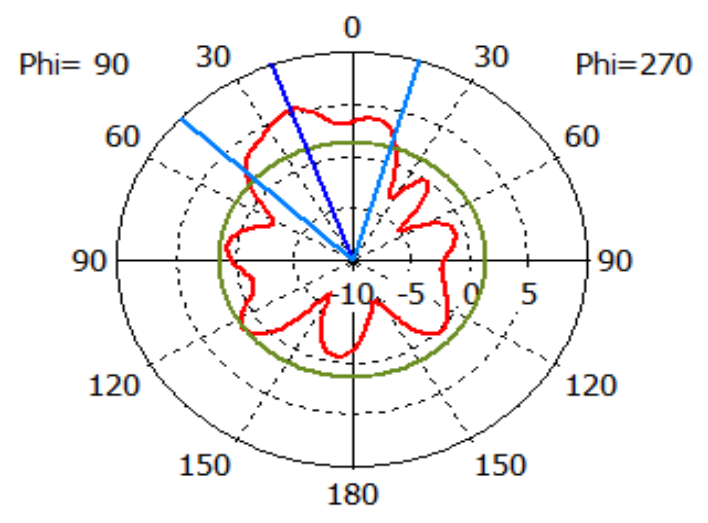

Theta / Degree vs. dBi
Farfield Directivity Abs (Theta $=90$ )

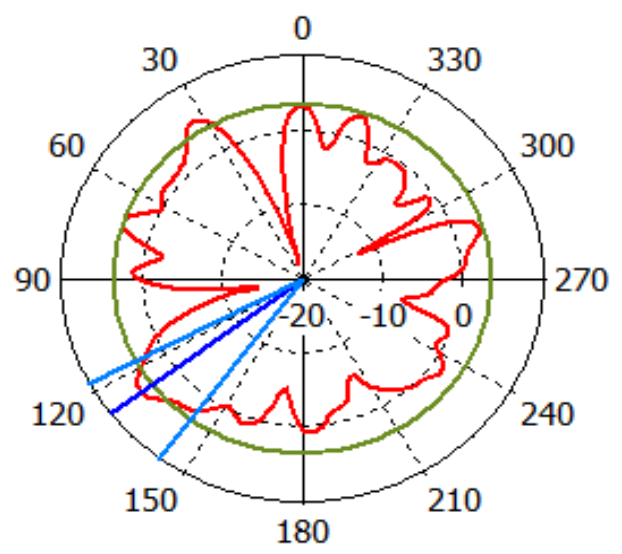

Phi / Degree vs. dBi

Fig.5. Radiation Pattern (a) $\mathrm{E}_{\text {Theta }}$ (b) $\mathrm{E}_{\mathrm{Phi}}$

From the figures, it can be observed that the radiation is maximum at an angle $20.0 \mathrm{deg}$ at resonating frequency of $28 \mathrm{GHz}$. The angular width of the radiation pattern at $3 \mathrm{~dB}$ is $63.1 \mathrm{deg}$ at $28 \mathrm{GHz}$.

\section{CONCLUSION}

In this paper, the design of a microstrip patch antenna with defected ground structure for $5 \mathrm{G}$ applications was presented. The proposed antenna resonates at $28 \mathrm{GHz}$ giving a wide impedance bandwidth of $3.2 \mathrm{GHz}$. Improved return loss characteristics are obtained by employing Defected Ground Structure. The proposed antenna is expected to have numerous applications in the modern communication system. The proposed design is suitable for stationary terminals of various indoor wireless communication networks.

\section{REFERENCES}

K. L. Wong (2002), Compact and Broadband Microstrip Antennas. New York: Wiley,.

Y. Huo, X. Dong, and W. Xu (2017), 5G cellular user equipment: From theory to practical hardware design, IEEE Access, vol. 5, pp. 13992-14010

Y. T. Lo, D. Solomon, and W. F. Richards (1979) Theory and experiment on microstrip antennas, IEEE Trans. Antennas Propag., vol. 27, pp.137145.

D. Guha, S Biswas, Chandrakanta K, Printed Antenna Designs Using Defected Ground Structures: A Review of Fundamentals and State-ofthe-Art Developments, Forum for Electromagnetic Research Methods and Application Technologies, pp.1-13. 
THE ANNALS OF "DUNĂREA DE JOS" UNIVERSITY OF GALATI

FASCICLE III, 2019, VOL. 42, NO. 1, ISSN 2344-4738, ISSN-L 1221-454X

KJ Babu, KSR Krishna, LP Reddy (2010) A Modified E Shaped Patch Antenna for MIMO Systems International Journal on Computer Science and Engineering Vol.2, pp-2427-2430.

M Y Talha, KJ Babu, RW Aldhaheri (2016) Design of a compact MIMO antenna system with reduced mutual coupling. International Journal of Microwave and Wireless Technologies Vol.8, pp-117-124.

Z.Ying (2012), Antennas in Cellular Phones for Mobile Communications, Proceedings of the IEEE, Vol.No. 100, pp. 2286-2296. 